\title{
Possible Role of Colonization and Cell Wall-Degrading Enzymes in the Differential Ability of Three Ulocladium atrum Strains to Control Botrytis cinerea on Necrotic Strawberry Leaves
}

\author{
Philippe Berto, M. Haïssam Jijakli, and Philippe Lepoivre
}

Unité de Phytopathologie, Faculté Universitaire des Sciences Agronomiques, 2, Passage des Déportés, B-5030 Gembloux, Belgium. Accepted for publication 26 June 2001.

\begin{abstract}
Berto, P., Haïssam Jijakli, M., and Lepoivre, P. 2001. Possible role of colonization and cell wall-degrading enzymes in the differential ability of three Ulocladium atrum strains to control Botrytis cinerea on necrotic strawberry leaves. Phytopathology 91:1030-1036.

Ulocladium atrum (strain 385) consistently reduced Botrytis cinerea sporulation on necrotic fragments of strawberry leaves. On these tissues, two strains of $U$. atrum (isolates 18558 and 18559) showed lower antagonistic activities than the reference strain 385 . Colonization of strawberry leaflets by the three $U$. atrum strains appeared similar in the absence of B. cinerea, whether quantified by chitin or immunological assays. The second method (based on anti- $U$. atrum antibodies) revealed that strawberry leaflet colonization by $U$. atrum 385 was better than by the other $U$. atrum strains in the presence of $B$. cinerea. An immunoassay using anti- $B$.
\end{abstract}

ABSTRACT

Botrytis cinerea Pers.:Fr., the causal agent of gray mold, is one of the most devastating pathogens in several crops worldwide. The abundant $B$. cinerea sporulation on dead and senescent plant tissues contributes to the development and the maintenance of an epidemic within a crop (31). The suppression of pathogen sporulation was proposed as a potential strategy of biological control (20, 32 ) to slow down epidemics of $B$. cinerea. Indeed, the application of the antagonistic strain 385 of the saprophytic fungus Ulocladium atrum $\mathrm{G}$. Preuss on leaf onion tips $(18,23)$ and cyclamen (21) consistently reduced both sporulation of $B$. cinerea and the development of symptoms on these crops.

Although experimental evidence is still missing, nutrient competition was suggested as a putative mechanism involved in the biocontrol activity of $U$. atrum B. cinerea sporulation (19). A reliable determination of biomass of fungi in vivo is needed to study interactions among biological control agent (BCA) and pathogens (9), as well as a method to evaluate nutrient competition itself. Two experimental strategies are reported to approach this problem. The first is based on the study of nutritive elements consumed by the antagonistic fungus during the biocontrol process, as previously performed by Filonow (12) on the model yeast- $B$. cinerea-apple. A second, indirect approach rests on the study of cell wall-degrading enzymes produced by the antagonistic fungus and presumably involved in the colonization (25). These enzymes contribute to release nutrients and are thus candidates as intermediary of competition between two organisms.

The present work compared the suppression of $B$. cinerea sporulation by different strains of $U$. atrum on necrotic strawberry

Corresponding author: M. H. Jijakli; E-mail address: jijakli.h@fsagx.ac.be

Publication no. P-2001-0904-01R

(C) 2001 The American Phytopathological Society cinerea antibodies revealed that the colonization of $B$. cinerea in tissues was lower in the presence of $U$. atrum 385 than with the two other $U$. atrum strains. The enzymatic activities produced by $U$. atrum 385 during the colonization phases of necrotic tissues were compared to $B$. cinerea and $U$. atrum strains 18558 and 18559. U. atrum 385 had the highest lipase, pectate lyase, and cellobiase activities while $B$. cinerea had the highest endo- $\beta$-1,4-glucanase activity. The study of lytic activities hydrolyzing the fungal cell wall revealed higher $\beta$-1,3-glucanase activity with $U$. atrum 385 , which was stimulated by $B$. cinerea on necrotic strawberry leaflets. These results suggest that plant and fungal cell wall-degrading enzymes produced by $U$. atrum 385 may play a complementary role in the competitive colonization of dead strawberry leaves against $B$. cinerea.

Additional keywords: gray mold, mode of action. leaves in relation to (i) tissue colonization and (ii) plant and fungal cell wall-degrading enzyme (PCWDE and FCWDE, respectively) activities.

\section{MATERIALS AND METHODS}

Fungi. B. cinerea (strain 700 isolated from a gerbera flower) and strain 385 of $U$. atrum (isolated from a tip of onion leaf) were received from the Institute of Plant Disease of Wageningen (The Netherlands). Two other U. atrum strains (MUCL 18558 and 18559) were obtained from La Mycothèque Universitaire catholique de Louvain-la-neuve (MUCL, Louvain-la-neuve, Belgium). All were cultured in petri dishes on oat meal agar $(20 \mathrm{~g}$ of oatmeal, $15 \mathrm{~g}$ of agar, $1,000 \mathrm{ml}$ of tap water) at $20^{\circ} \mathrm{C}$ for 14 days. Conidial suspensions were obtained by flooding the colonies with sterile tap water containing $0.01 \%$ Tween 80 , rubbing the removal conidia from fungal colonies, and filtering through a sterile nylon gauze with a mesh of $200 \mu \mathrm{m}$. The conidial suspensions were diluted to the required concentrations as determined with a Bürker cell.

Plant material. Strawberry plants (cv. Elsanta, provided by the Biotechnological Department of Gembloux) were grown in the greenhouse at $25^{\circ} \mathrm{C}$ with a photoperiod of $16 \mathrm{~h}$.

Bioassays. Healthy green leaflets of strawberry were harvested in the greenhouse from 4-week-old plants, sterilized by gamma radiation of 40 krays (irradiator Gammacell 220 Co-60; GriffithMediris, Fleurus, Belgium), dried at room temperature under sterile atmosphere for 3 weeks, and stored in sealed plastic bags. Before using them for bioassay, leaflets were rehydrated with sterile tap water overnight and were washed thoroughly to remove soluble nutrients. Four washed leaflets were then placed in a petri dish ( $9 \mathrm{~cm}$ in diameter) on $0.75 \%$ water agar (wt/vol). The suspension of $B$. cinerea conidia $\left(10^{4}\right.$ spores $\left./ \mathrm{ml}\right)$ was sprayed to the leaf surface to deposit $5 \mu \mathrm{l}$ per centimeter of area. After either 0 or $12 \mathrm{~h}$ at $20^{\circ} \mathrm{C}$ under a 16 -h photoperiod, conidia of the antagonist 
$\left(2 \times 10^{6}\right.$ spores per $\left.\mathrm{ml}\right)$ were applied on the inoculated leaves as described for $B$. cinerea.

The protective effect of $U$. atrum strains (385, 18558, and 18559 ) was quantified by counting $B$. cinerea conidia produced after 6 days of colonization. For this purpose, four leaflet disks $\left(10 \mathrm{~cm}^{2}\right)$, cut with a cork-borer from one leaflet, were shaken in $20 \mathrm{ml}$ of tap water containing $0.1 \%$ Tween 20 . The number of $B$. cinerea conidia was determined with a Bürker cell (Marienfeld, Lauda-Königshofen, Germany) and expressed per square centimeter of leaflet surface. The detection limit (one single spore observed in the Bürker cell) corresponds theoretically to 15,625 conidia $/ \mathrm{cm}^{2}$ of leaf surface (calculated from the $10 \mathrm{~cm}^{2}$ of leaf surface per replication). Data were means of four independent experiments over time with four replicates each, one replicate corresponding to one leaflet.

Measurement of fungal growth. The leaf treatment with $U$. atrum strains and $B$. cinerea was performed as described previously. The mycelial growth of $U$. atrum on dead strawberry leaflets was first determined in the absence of $B$. cinerea by the quantification of chitin content as described by Ride and Drysdale (27). The chitin content was expressed as glucosamine equivalents per square centimeter of leaflet area. This experiment was repeated independently three times, with two replicates each.

$U$. atrum colonization of dead strawberry leaflets was also quantified in absence and in presence of $B$. cinerea by plate trapped antibodies (PTA) enzyme-linked immunosorbent assay (ELISA) (17) using specific monoclonal anti-U. atrum antibodies Ua-PC3 received from M. Dewey (Oxford, UK). U. atrum strains and $B$. cinerea were applied simultaneously on leaf tissues. Standard curves have been performed for each $U$. atrum strain according to the incubation time (up to 6 days) in $1 \%$ (wt/vol) strawberry leaf extract medium (dead leaves ground in distilled sterile water). Standard curves have been performed up to 6 days of incubation using the strawberry leaf medium and were selected at 3 and 6 days for conversion of ELISA data from days 0 to 3 and days 4 to 6 of $U$. atrum colonization, respectively.

Similarly, B. cinerea colonization was assayed during 6 days of leaf colonization after a simultaneous inoculation with one of the $U$. atrum strains. Specific monoclonal anti- $B$. cinerea antibodies AD-Bc6 received from M. Dewey (Oxford, UK) were used for the immunoquantification. Lyophilized mycelium harvested from a 3 -week-old liquid culture of $2 \%(\mathrm{wt} / \mathrm{vol})$ oat meal agar, $B$. cinerea, or $U$. atrum (strain 385,18558 , or 18559) was used as reference standard in this immunoassay. The experiments based on PTA-ELISA were repeated independently two times with two replicates each.

Extract preparation. For the PCWDE and FCWDE activity assays, homogenates of leaflet disks $\left( \pm 40 \mathrm{~cm}^{2}\right.$ except for lipolytic assay, $\pm 100 \mathrm{~cm}^{2}$ ) colonized by one of the $U$. atrum strains or by $B$. cinerea were prepared according to the method of Somé and Tivoli (30). The extracts were frozen at $-20^{\circ} \mathrm{C}$ before further enzymatic assays.

Enzyme assays. CWDE activities produced during the strawberry leaf colonization by $B$. cinerea or $U$. atrum were followed after growing incubation periods (from 0 to 6 days). All the results dealing with the enzymatic assays were means of two independent experiments with two replicates each.

Lipase (EC 3.1.1.3) activity was quantified by titrimetric assay using an emulsion of olive oil as substrate (5). The olive oil emulsion was first stirred to get an emulsion which remained stable for at least $1 \mathrm{~h}$. Incubations were performed for $16 \mathrm{~h}$ at $20^{\circ} \mathrm{C}$. The reaction was stopped by addition of $10 \mathrm{ml}$ of an ethanol-acetone mixture $(1: 1, \mathrm{vol} / \mathrm{vol})$ and $0.1 \mathrm{ml}$ of phenolphthalein indicator solution $(0.375 \%$ in methanol). One specific unit (SU) of lipase activity was defined as the amount of enzyme causing the release of $1 \mathrm{mmol}$ of oleic acid per minute and per milligram of protein.

Pectate lyase (EC 4.2.2.2) hydrolyses pectate by transelimination, resulting in the release of double-bond substances. The pec- tate lyase (PL) activity was measured spectrophotometrically at $235 \mathrm{~nm}$ (34). One SU was defined as the amount of enzyme that caused an increase of 2.6 in absorbance at $235 \mathrm{~nm}$, equivalent to the release of $1-\mu \mathrm{mol}$ aldehyde groups per milligram of protein for specific activity (35), after $16 \mathrm{~h}$ of incubation.

The activity of cellobiase (EC 3.2.1.21) was determined using the glucose hexokinase method (Glucose/HK kit; Sigma, Bornem, Belgium). The spectrophotometric reading was carried out at $340 \mathrm{~nm}$. The glucose concentration of the samples was determined using a concentration range of D-glucose ( 0 to $300 \mu \mathrm{g})$ as a standard. One SU of the cellobiase activity was defined as the amount of enzyme causing the release of $1 \mathrm{mmol}$ of glucose per hour and per milligram of protein.

The activity of endo- $\beta$-1,4-glucanase (EC 3.2.1.4) was measured according to a colorimetric method utilizing xyloglucan $(\mathrm{XG})$ as substrate (29). After circular stirring $(125 \mathrm{rpm})$ at $40^{\circ} \mathrm{C}$ for $16 \mathrm{~h}$, the absorbance of the samples was measured against blank (sample without XG) at $640 \mathrm{~nm}$. The endo- $\beta$-1,4-glucanase activity was expressed in arbitrary units (AU) as follows: $\mathrm{AU} / \mathrm{ml}=[(A c-$ $A s) / A c] \times 100$, where $A c$ is the absorbance of the control per milliliter (containing XG with no enzyme) and $A s$ the absorbance of the leaf homogenate (per milliliter). The SU was expressed in $\mathrm{AU} / \mathrm{h}$ and AU/mg of protein.

The total activity of $\beta$-1,3-glucanase, including the endo- (EC 3.2.1.39) and the exo- (EC 3.2.1.58) form, was assayed spectrophotocally at $550 \mathrm{~nm}$ by the dinitrosalicylic procedure (33) modified as follows: the reaction mixture was prepared with $0.9 \mathrm{ml}$ of $1 \%(\mathrm{wt} / \mathrm{vol})$ laminarin in potassium acetate buffer $(\mathrm{pH} 5.2)$ containing $0.02 \%(\mathrm{wt} / \mathrm{vol})$ sodium azide and $0.1 \mathrm{ml}$ of leaf homogenate. The reaction mixture was incubated at $37^{\circ} \mathrm{C}$ with continuous stirring $(125 \mathrm{rpm})$ for $16 \mathrm{~h}$. One SU of $\beta$-1,3-glucanase activity was defined as the amount of enzyme causing the release of $1 \mathrm{mg}$ of glucose per minute and per milligram of protein under the assay conditions. For this enzymatic assay, $U$. atrum strains $(385,18558$, and 18559) were applied on leaflets untreated or precolonized for $24 \mathrm{~h}$ by $B$. cinerea. After the period of incubation of $24 \mathrm{~h}$ at $20^{\circ} \mathrm{C}, \mathrm{B}$. cinerea on necrotic tissues was killed by treatment with gamma rays (40 krays).

Protein determination. Protein concentration was determined according to Bradford (4) using the Bio-rad protein assay kit (Nazareth, Belgium). Bovin serum albumin was used as standard.

Statistical analyses. Data on the number of $B$. cinerea conidia, observed after 6 days of dead leaf tissue colonization in the presence of different strains of $U$. atrum $(385,18558$, or 18559) were subjected to analysis of variance (ANOVA) after log transformation. The contrast analysis allowed comparison between the effect of each $U$. atrum strain in relation with the other ones when they were applied simultaneously or $12 \mathrm{~h}$ after $B$. cinerea inoculation. Values of $U$. atrum colonization (chitin or immunoassays) were also submitted to statistical analysis using univariate ANOVA to perform the analysis by comparison of treatments for each time of colonization $(1,2,3,4$, and 6 days). Data corresponding to time 0 were null whatever the treatment and not taken into account. When a significant difference was established, the SnedecorNewman-Keuls test allowed the multiple mean comparison.

Split-plot ANOVA was also performed considering parameters of "time" and "experiment" as blocks; treatment-experiment interaction was used as error a, whereas time-experiment interaction together with treatment-time-experiment interaction were considered as error $\mathrm{b}$ for the determination of $F$ value and statistical significance (data not shown). All these statistical procedures were performed using the SYSTAT 5 program (SPSS Inc., Chicago).

\section{RESULTS}

Comparison of the antagonistic activity of $\boldsymbol{U}$. atrum strains $(385,18558$, and 18559). A reduction of $B$. cinerea sporulation was observed on necrotic fragments of strawberry leaves when $U$. 
atrum 385, U. atrum 18558, and $U$. atrum 18559 were applied (Fig. 1). Whatever the incubation period between $B$. cinerea inoculation and $U$. atrum application $(0 \mathrm{~h}$ and $12 \mathrm{~h}), U$. atrum 18558 and $U$. atrum 18559 exhibited a significantly lower antagonistic activity ( $F$ was significant at $P=0.0001$ ) than $U$. atrum strain 385. The comparison of $F$ values also revealed that this difference was more significant when $U$. atrum strains and $B$. cinerea were applied simultaneously $(F=126.67)$, in comparison with $F=29.35$ obtained when $U$. atrum strains were applied $12 \mathrm{~h}$ after B. cinerea.

Quantification of $\boldsymbol{U}$. atrum and $\boldsymbol{B}$. cinerea colonization. The chitin content in tissues colonized by $U$. atrum 385 alone increased slightly up to $1.98 \mu \mathrm{g}$ glucosamine equivalents per square centimeter of leaflet area after $48 \mathrm{~h}$ of incubation (Fig. 2A). The values of chitin content reached $6.1 \mu \mathrm{g}$ equivalents per square centimeter after 6 days of incubation. Chitin contents measured for the two other strains of $U$. atrum were slightly lower but not significantly different than with $U$. atrum 385 using univariate ANOVA $(F=0.66$ at $P=0.05)$. In the absence of $B$. cinerea, similar colonization by the three $U$. atrum strains was confirmed statistically using the PTA-ELISA method $(F=0.63$ at $P=0.05)$. These results were confirmed by split-plot ANOVA (data not shown).

In the presence of $B$. cinerea, the $U$. atrum 385 content $(4.98 \mathrm{mg} / \mathrm{ml})$ was higher $(2.5$-fold $)$ than the amount of $U$. atrum strain 18559 and $U$. atrum strain 18558 after 6 days of colonization (Fig. 3A). Univariate ANOVA indicated the difference was significant $(F=20.04, P=0.047)$ after 6 days of colonization. The comparison by Snedecor-Newman-Keuls test between leaf treatments with different $U$. atrum strains confirmed that the colonization by $U$. atrum 385 was significantly higher than the two other $U$. atrum strains $(P=0.05)$.

On the other hand, the measurement of $B$. cinerea colonization by PTA-ELISA on necrotic strawberry leaflets revealed similar colonization profiles when $B$. cinerea was inoculated alone or in the presence of the strains 18558 and 18559 (Fig. 3B). In contrast, the amount of $B$. cinerea mycelium was significantly lower (approximately five times) in the presence of the reference strain 385 after 6 days of incubation. This significance was established by univariate ANOVA $(F=11.97$ at $P=0.035)$, followed by Snedecor-Newman-Keuls test $(P=0.05)$. Splitplot ANOVA confirmed the significant difference $(F=15.372$ at $P=0.05)$.

Activities of PCWDEs produced by $B$. cinerea and the three $U$. atrum strains during the different stages of strawberry leaf colonization. Nine classes of enzymatic activities involved in the degradation of plant cell walls were estimated in homogenates extracted from strawberry necrotic tissues colonized by $U$. atrum alone (strains 385, 18558, or 18559). Similar activities of nonspecific esterase, cutinase, lipase, pectin lyase $(\mathrm{PnL})$, polygalacturonase (PG), and pectin methyl esterase (PME) were detected in extracts of tissue treated with $U$. atrum whatever the strain (data not shown). Only lipase, PL, cellobiase, and $\beta$-1,4-glucanase exhibited higher activities in extracts of tissue colonized by the most efficient antagonistic strain 385 of $U$. atrum in comparison with other strains. These four enzymatic activities were compared to those produced by $B$. cinerea alone on necrotic strawberry leaflets (Fig. 4).

The lipolytic specific activity showed a sharp peak in the strawberry leaflets after $12 \mathrm{~h}$ of colonization by $U$. atrum 385 , whereas the activity was not detected in extracts of leaflets colonized by the two other strains (18558 or 18559) and by $B$. cinerea (Fig. 4A).

After 2 days of colonization, the extracts of strawberry leaflets colonized by $U$. atrum 385 exhibited the highest PL specific activity (9.16 SU). Then, the activity rapidly decreased to reach 3 SU after 4 days. In contrast, activity profiles in extracts of leaflets colonized by the other strains (U. atrum 18558 and $U$.

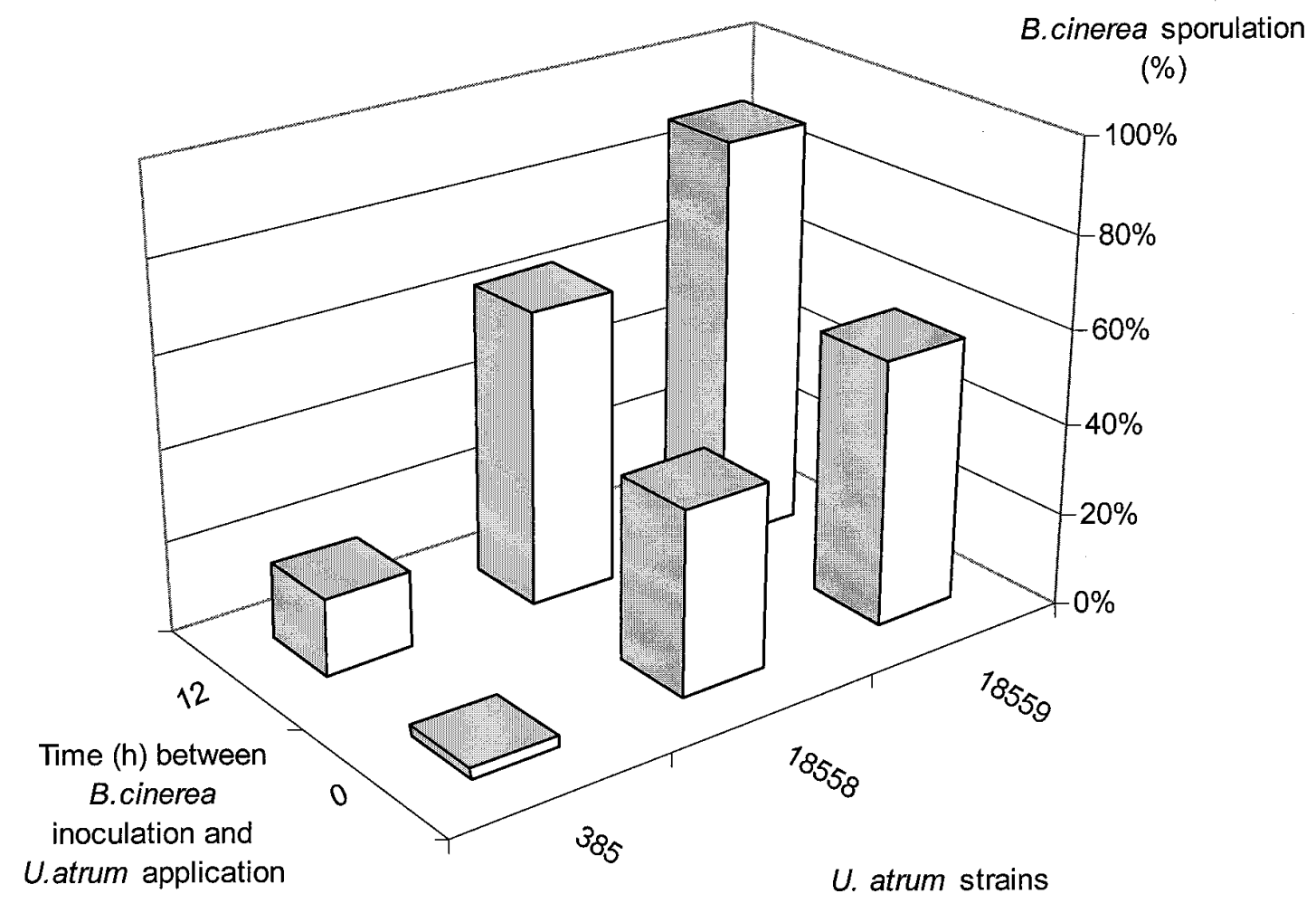

Fig. 1. Effect of different Ulocladium atrum strains (isolates 385, 18558, and 18559) on number of Botrytis cinerea spores produced on necrotic fragments of strawberry leaves. Conidial concentrations of $B$. cinerea inoculation and $U$. atrum (strains 385,18558 , and 18559 ) application were adjusted to $10^{4}$ spores/ml and $2 \times 10^{6}$ spores $/ \mathrm{ml}$, respectively, at a sprayed volume of $\approx 5 \mu \mathrm{l} / \mathrm{cm}^{2}$ of leaf area. B. cinerea sporulation was determined with a Bürker cell from washings of four leaflet disks $\left(10 \mathrm{~cm}^{2}\right)$ cut after 6 days of colonization. Mean percentage of $B$. cinerea sporulation is expressed in percent of the control and is the result of four independent experiments with four replicates each. 
atrum 18559) revealed a slighter increase after 2 days of incubation $(\approx 2 \mathrm{SU})$ and then slowly decreased for the whole period of the experiment (Fig. 4B). There was no difference between the extracts prepared from leaflets colonized by the different strains $(385,18558$, or 18559$)$ after 4 days. During the same period, low PL activity was detected in $B$. cinerea extracts $(\approx 0.5 \mathrm{SU})$ in comparison with the activity measured the second day with $U$. atrum 385 or with both of the other $U$. atrum strains.

Cellobiase specific activity went up steadily from $48 \mathrm{~h}$ to 6 days, when it reached $\approx 5 \mathrm{SU}$ in extracts of strawberry leaflets colonized by $U$. atrum 385 . After 4 days of colonization, the increase was three times higher in leaf extracts colonized by $U$. atrum 385 than by the other $U$. atrum strains (Fig. 4C). Low cellobiase activity $(\approx 0.5 \mathrm{SU})$ was measured in dead strawberry leaflets colonized by $B$. cinerea whatever the incubation time. After 6 days, a 10-fold higher activity was observed in $U$. atrum 385 extracts than in $B$. cinerea extracts.

The endo- $\beta$-1,4-glucanase profiles of all $U$. atrum strains remained stable at $\approx 60 \mathrm{SU}$ for the first 4 days. Then, the specific activity of extracts from $U$. atrum 385 -colonized leaflets continued to increase and reached 116.9 SU after 6 days, while the
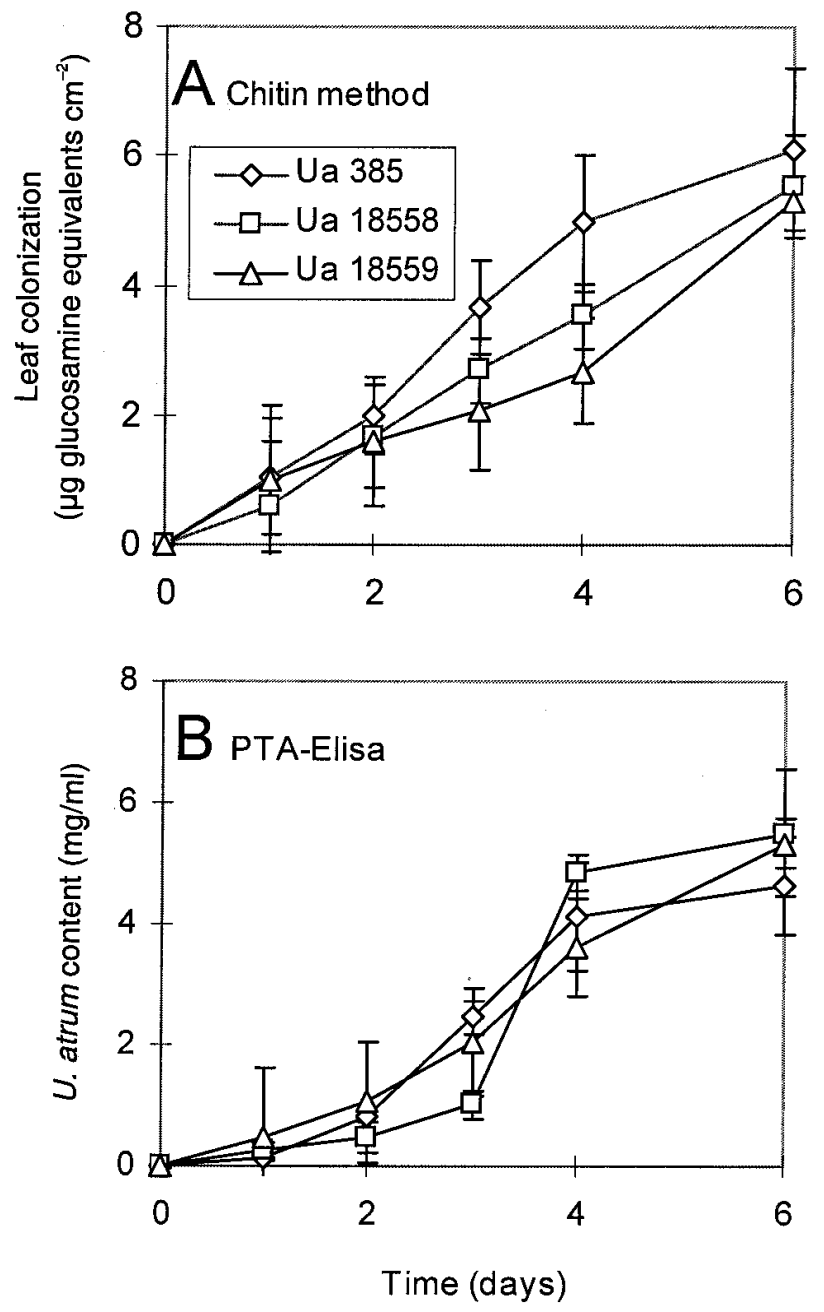

Fig. 2. Comparison of necrotic strawberry leaflet tissues colonization by three Ulocladium atrum strains $(385,18558$, and 18559) in the absence of Botrytis cinerea. U. atrum (strains 385,18558 , and 18559) was applied at a concentration of $2 \times 10^{6}$ spores $/ \mathrm{ml}$ on dead leaf tissues by spraying $5 \mu \mathrm{l} / \mathrm{cm}^{2}$ of leaf area. A, Quantification of colonization by chitin content method. Data are means of three independent experiments with two replicates each. B, Immunoquantification of leaf colonization by plate trapped antibodies enzymelinked immunosorbent assay using specific anti- $U$. atrum antibodies. Data are means of two independent experiments with two replicates each. Vertical bars represent standard error of the mean. activity remained unchanged for the other strains (isolates 18558 and 18559). In contrast, the endo- $\beta$-1,4-glucanase activity in tissues colonized by $B$. cinerea was much higher throughout the 6 days of incubation (Fig. 4D). The highest value was recorded after 3 days (5,573 SU).

Assays of fungal cell wall-degrading enzymes. Residual activities were detected in control extracts (leaflets precolonized only by $B$. cinerea) and were subtracted from the activities linked to $U$. atrum colonization on B. cinerea precolonized leaflets (Fig. 5). Regardless of the time of precolonization of B. cinerea $(0$ or $24 \mathrm{~h})$, the $\beta$-1,3-glucanase activity measured after 4 and 6 days of incubation in extracts of leaflets colonized by $U$. atrum 385 was significantly higher than in extracts of leaflets colonized by the other $U$. atrum strains (Fig. 5A). The $\beta$-1,3-glucanase activity linked to $U$. atrum 385 colonization was increased twofold (7.95 SU) in the presence of $B$. cinerea biomass on necrotic tissues of strawberry (Fig. 5B) as compared with activity in the absence of B. cinerea (3.30 SU) (Fig. 5A). Similar results were obtained on leaflets with $12 \mathrm{~h}$ of $B$. cinerea precolonization (data not shown). No stimulating effect was observed with the strains 18558 and 18559 of $U$. atrum.
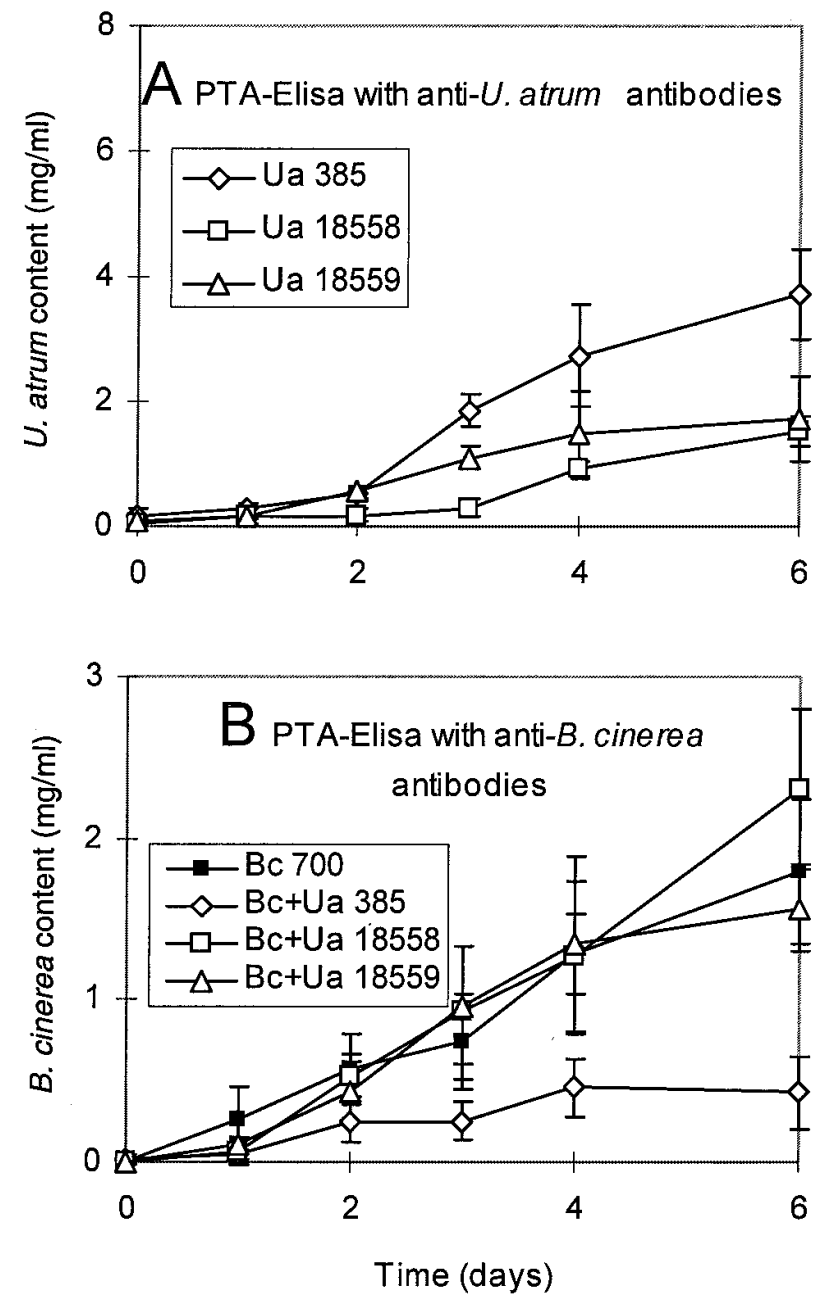

Fig. 3. Comparison of leaflet tissues colonized by three Ulocladium atrum strains $(385,18558$, and 18559$)$ or by Botrytis cinerea in antagonistic condition. Conidial concentrations of $B$. cinerea inoculation and $U$. atrum (strains 385,18558 , and 18559) application were adjusted to $10^{4}$ spores $/ \mathrm{ml}$ and $2 \times$ $10^{6}$ spores $/ \mathrm{ml}$, respectively, at a sprayed volume of $5 \mu \mathrm{l} / \mathrm{cm}^{2}$ of leaf area. $B$. cinerea and $U$. atrum were sprayed simultaneously on dead strawberry leaflets. A, Immunoquantification of strain 385,18558 , or 18559 of $U$. atrum in the presence of $B$. cinerea. $\mathbf{B}$, Immunoquantification of $B$. cinerea in the presence or absence of $U$. atrum. Data are means of two independent experiments with two replicates each. Vertical bars represent standard error of the mean. 


\section{DISCUSSION}

$U$. atrum 385 was first isolated by Köhl et al. $(22,23)$ for its ability to suppress $B$. cinerea sporulation on necrotic onion tips and lily leaves. This antagonistic effect of $U$. atrum was confirmed with stem wounds of tomato in greenhouse crops (13) and with grapevine in field conditions (28). The efficacy of $U$. atrum against $B$. cinerea has not been tested on strawberry leaves yet, although $U$. atrum showed a potential to reduce fruit rot on strawberry (20). Our results confirmed the antagonistic effect of $U$. atrum on this model by reducing the $B$. cinerea sporulation on necrotic leaves. Such reduction in production of Botrytis inoculum by application of $U$. atrum 385 can contribute to slow down the gray mold epidemy spread when the population of $B$. cinerea is developing independently of exogenous inoculum (18). On the other hand, we revealed that two other $U$. atrum strains (18558 and 18559) were consistently less effective.

Classical techniques are limited in their ability to quantify mycelial development on plant substrates by different fungi $(2,8)$. Although chitin is strictly associated with the fungal cell wall (27), its assessment cannot distinguish between the pathogen and the antagonist present on the same biological niche. On the other hand, immunoquantification methods developed by KarpovitchTate et al. (18) allowed specific monitoring of the growth of $U$. atrum or B. cinerea in strawberry necrotic tissues in the presence of the other fungal competitor in biocontrol conditions.

The respective mycelial development of the three $U$. atrum strains on dead strawberry tissues was first evaluated without the pathogen and appeared similar in term of chitin content. This similar colonization of leaf tissues by the $U$. atrum strains observed with chitin assays in the absence of $B$. cinerea was confirmed by immunoassays. In contrast, when $U$. atrum and $B$. cinerea colonized the leaves together, the better colonization of $U$. atrum 385 in comparison with the other $U$. atrum strains established the best biocontrol efficacy of the reference strain 385 . Moreover, the $B$. cinerea leaf colonization was reduced in the presence of $U$. atrum 385 compared to that observed alone or in presence of the less efficient strains of $U$. atrum (18558 and 18559), suggesting a close relationship between biocontrol efficacy and level of colonization both by the antagonist and the pathogen.

Filonow (12) used a radioactive labelling technique to show that nutrient competition was involved in biocontrol, with antagonistic yeasts against $B$. cinerea assimilating ${ }^{14} \mathrm{C}$-sucrose more rapidly than the pathogen. The study of CWDE associated with the colonization of necrotic tissues represents an alternative used in this article to tentatively connect competitive colonization with competition for nutritive elements.

Three PCWDEs (lipase, PL, and cellobiase) were proposed as candidates which could be involved in the competition, due to their higher enzymatic activities in leaf extracts colonized by $U$. atrum 385 than by $U$. atrum strains or B. cinerea. Enzymatic activities of nonspecific esterase, cutinase, PME, PG, and pectin lyase produced by $U$. atrum 385 were also compared to those of the other $U$. atrum strains, but the levels were low and they did not appear to be involved in the increased efficiency of the colonization of strawberry leaf tissue by U. atrum 385 .
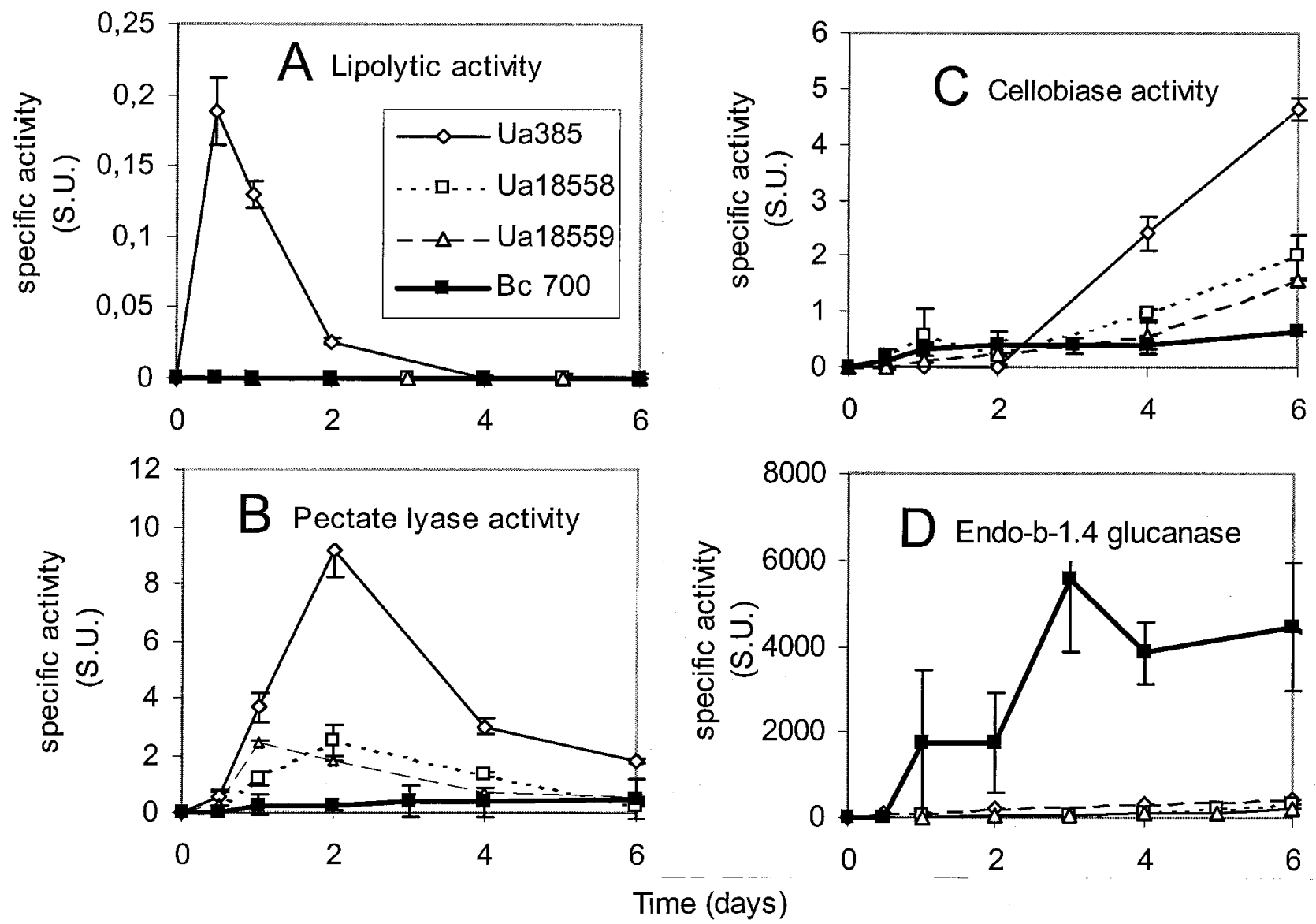

Fig. 4. Specific activities of plant cell wall-degrading enzymes in extracts of strawberry necrotic leaflets after growing periods of colonization by one of the three different Ulocladium atrum strains $\left(385,18558\right.$, or 18559) or by Botrytis cinerea. B. cinerea inoculation ( $10^{4}$ spores $\left./ \mathrm{ml}\right)$ and $U$. atrum application (strains 385,18558 , and 18559 at $2 \times 10^{6}$ spores $/ \mathrm{ml}$ ) were simultaneously sprayed at $5 \mu \mathrm{l} / \mathrm{cm}^{2}$ of leaf area on dead strawberry leaflets. A, Lipolytic activity, B, pectate lyase activity, $\mathbf{C}$, cellobiase activity, and $\mathbf{D}$, endo- $\beta-1,4$-glucanase activity. Respective specific units (SU) are detailed in Materials and Methods section. Data on $U$. atrum 385 extracts are means of three experiments with three replicates each. Data on B. cinerea and $U$. atrum 18558 and 18559 extracts are means of two experiments with two replicates each. Vertical bars represent standard error of the mean. 
A lipolytic activity was reported to be involved in the first steps of plant infection of $B$. cinerea (5), and Garcia-Lepe et al. (14) proposed that lipase activity could be also involved in fungal autolysis. In the framework of our study, lipase could be associated with the biocontrol effectiveness of $U$. atrum. Its exclusive detection during the first $24 \mathrm{~h}$ of $U$. atrum colonization suggested a relation with esterified polymers degradation of plant epicuticular waxes or cutin (1). This phenomenon does not support the hypothesis of a synergistic action of lipase with other FCWDE (3) by exolysis on $B$. cinerea cell membrane degradation.

$\mathrm{PL}$ is considered as a major enzyme for hydrolyzing pectin polymers (15), although the pectin degradation appeared more successful when PL was acting synergistically with pectin lyase and pectin methyl esterase (16). The last selected PCWDE was cellobiase, able to degrade cellobiose, a dimer of glucose, into a glucose unit. Cellobiose is released with other oligomers after the enzymatic hydrolysis of cellulose layers of plant cell walls by $\beta$ 1,4 -glucanases (7). In this study, endo- $\beta$ - 1,4 -glucanase and cellobiase activities were only detected after 4 days of colonization, when all the pectinolytic enzymes have been detected (6). Endo$\beta$-1,4-glucanase was dismissed from our selection of candidate enzymes involved in antagonistic properties of $U$. atrum according to the important levels of activity produced by $B$. cinerea during strawberry leaf colonization, compared with the endo- $\beta$ 1,4-glucanase activities produced by $U$. atrum strains. However,
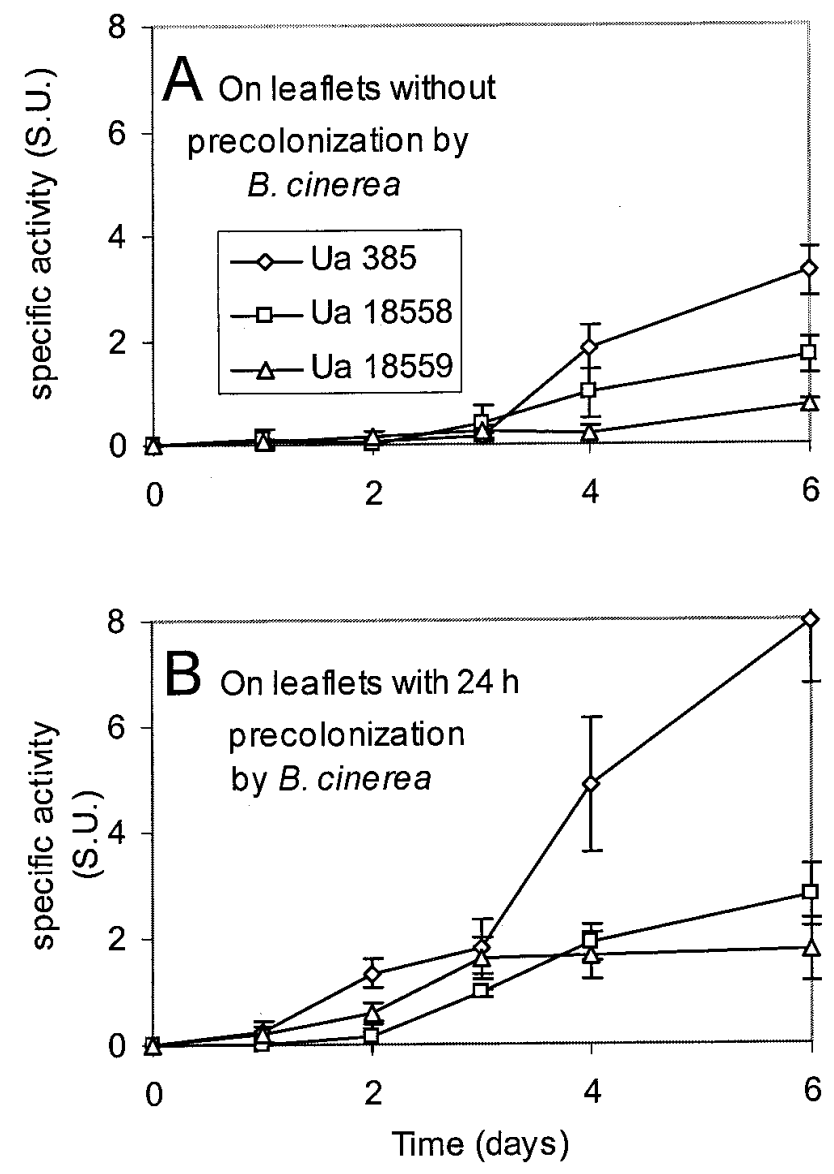

Fig. 5. $\beta-1,3-$ Glucanase activity produced by different strains of Ulocladium atrum $(385,18558$, and 18559) on strawberry necrotic leaflets precolonized by $B$. cinerea. After increasing period of incubation $(\mathbf{A}, 0 \mathrm{~h}$ and $\mathbf{B}, 24 \mathrm{~h})$ at $20^{\circ} \mathrm{C}$, Botrytis cinerea on necrotic tissues was killed by treatment with gamma rays (40 krays). U. atrum strains $(385,18558$, and 18559$)$ were then applied on these precolonized leaflets. One specific unit of $\beta$-1,3-glucanase activity was defined as $1 \mathrm{mg}$ of glucose released per hour and per milligram of protein. Data are means of two experiments with two replicates. Vertical bars represent standard error of the mean. cellobiose produced by hydrolysis of cellulose caused by $B$. cinerea $\beta$-1,4-glucanases could be preferentially used by $U$. atrum 385 , which revealed higher cellobiase activity than the other $U$. atrum strains. This observation is in agreement with the similar strawberry leaflet colonization by the three $U$. atrum strains in the absence of $B$. cinerea, but does not exclude a possible synergistic effect between endo- $\beta$-1,4-glucanase and cellobiase activities produced by $U$. atrum 385 .

The involvement of two or more mechanisms has been demonstrated in several antagonistic systems (24). FCWDEs are associated with degradation of hyphae of many pathogens (11), but few results dealing with this phenomenon in relation to $B$. cinerea are reported. In this context, the specific stimulation of higher $\beta-1,3-$ glucanase activity produced by $U$. atrum 385 (compared with $U$. atrum strains 18558 and 18559) on leaf extracts precolonized by $B$. cinerea could play an additional role in the antagonistic strategy of $U$. atrum 385 against $B$. cinerea. Nevertheless, the function of the $\beta$-1,3-glucanase activity enhancement remains unclear. This enhancement could rest on the direct interaction between $U$. atrum 385 and $B$. cinerea, but could also result in a metabolic process (26), leading to a better dead cell wall degradation of either $B$. cinerea or $U$. atrum itself. The endochitinase activity was also measured in the same extracts prepared for the $\beta$-1,3-glucanase assays. No significant difference was observed between the different strains (data not shown). Therefore endochitinase activity should not be involved in the antagonism of $U$. atrum. The production of enzymes that degrade $B$. cinerea cell wall have already been observed $(10,17)$. However, the importance of mycoparasitism in biocontrol of $B$. cinerea in vivo is open to doubt because it may be too slow to be effective alone against a pathogen that germinates and colonizes host tissues quickly (11).

The finding that $U$. atrum 385 colonized the strawberry necrotic tissues more extensively than two other strains with lower antagonistic activities only when the pathogen is present highlights the contribution of competitive colonization in biological control. However, our data underlined the complexity of mechanisms involved in the biological suppression of $B$. cinerea sporulation. Competitive colonization, regarded as an important mechanism in biocontrol strategy of $U$. atrum, does not exclude a combination with another mechanism, involving FCWDE activity. Moreover, toxins or other secondary metabolites produced by $B$. cinerea could interact differently on the physiology of the different $U$. atrum strains during the strawberry leaf colonization and reveal a variation in sensitivity of $U$. atrum strains.

Our results on differential colonization and CWDE activities of $U$. atrum strains associated with strawberry necrotic tissues suggested that nutritive competition could play a role in the mechanism of mode of action, as previously proposed by Köhl et al. (19). To confirm the importance of CWDE, additional studies are needed on the impact of stimulation of CWDE activities on the protection of $U$. atrum 385 against $B$. cinerea. The use of mutants disrupted in production of specific enzymes could complete these studies, but this second approach will require the genetic characterization of $U$. atrum 385 and the development of molecular tools.

\section{ACKNOWLEDGMENTS}

This work was supported by an EC grant from the European program FAIR 3 CT96-1898. We thank M. Dewey and N. Karpovitch-Tate for donation of anti- $U$. atrum antibodies and assistance in PTA-ELISA assays; R. Oger and V. Planchon for statistical assistance; and J. Köhl for his helpful comments.

\section{LITERATURE CITED}

1. Annis, S. L., and Googwin, P. H. 1997. Recent advances in the molecular genetics of plant cell wall-degrading enzymes produced by plant pathogenic fungi. Eur. J. Plant Pathol. 103:1-14. 
2. Bermingham, S., Maltby, L., and Cooke, R. C. 1995. A critical assessment of the validity of ergosterol as an indication of fungal biomass. Mycol. Res. 99:479-484.

3. Bertagnolli, B. L., Dal Soglio, F. K., and Sinclair, J. B. 1996. Extracellular enzyme profiles of the fungal pathogen Rhizoctonia solani isolate 2B-12 of two antagonists, Bacillus megaterium strain B153-2-2 and Trichoderma harzianum isolate Th008.I. Possible correlations with the inhibition of growth and biocontrol. Physiol. Mol. Plant Pathol. 48:145-160.

4. Bradford, M. M. 1976. A rapid and sensitive method for the quantification of microgram quantities of proteins utilizing the principle of protein-dye binding. Anal. Biochem. 72:248-254.

5. Comménil, P., Belingheri, L., and Dehorter, B. 1998. The prevention of infection of tomato leaves by Botrytis cinerea using polyclonal antibodies against a lipase. Physiol. Mol. Plant Pathol. 52:1-14.

6. Cooper, R. M. 1983. The mechanisms and significance of enzymic degradation of host cell walls by parasites. Pages 101-135 in: Biochemical Plant Pathology VII. J. A. Callow, ed. Wiley-Interscience Publication, Chichester, NY.

7. Cooper, R. M., and Rankin, B. 1978. Cell wall-degrading enzymes of vascular wilt fungi. II. Properties and modes of action of polysaccharidases of Verticillium albo-atrum and Fusarium oxysporum f. sp. lycopersici. Physiol. Mol. Plant Pathol. 13:101-134.

8. Cousin, M. A. 1996. Chitin as a measure of mold contamination of agricultural commodities and foods. J. Food Prot. 59:73-81.

9. Dewey, F. M., Thornton, C. R., and Gilligan, C. A. 1997. Use of monoclonal antibodies to detect, quantify and visualise fungi in soils. Adv. Bot. Res. 24:276-308.

10. Dubos, B. 1992. Biological control of Botrytis: State-of-the-art. Pages 169-178 in: Recent Advances in Botrytis Research. K. Verhoeff, N. E. Malathrakis, and B. Williamson, eds. Pudoc Scientific Publishers, Wageningen, the Netherlands.

11. Elad, Y. 1996. Mechanisms involved in the biological control of Botrytis cinerea incited diseases. Eur. J. Plant Pathol. 102:719-732.

12. Filonow, A. B. 1998. Role of competition for sugars by yeasts in the biocontrol of gray mold of apple. Biocontrol Sci. Technol. 8:243-256.

13. Fruit, L., and Nicot, P. 1999. Biological control of Botrytis cinerea stem wounds with Ulocladium atrum. Integrated Control in Glasshouses IOBC Bull. 22:81-84.

14. Garcia-Lepe, R., Nuero, O. M., Reyes, F., and Santamaria, F. 1997. Lipases in autolyzed cultures of filamentous fungi. Lett. Appl. Microbiol. 25:127-131.

15. Hayashi, K., Inoue, Y., Shiga, M., Sato, S., Takano, R., Hirayae, K., Hibi, T., and Hara, S. 1997. Pectinolytic enzymes from Pseudomonas marginalis Maff 03-01173. Phytochemistry 45:1359-1363.

16. Howell, C. R. 1976. Use of enzyme-deficient mutants of Verticillium dahliae to assess the importance of pectolytic enzymes in symptom expression of Verticillium wilt of cotton. Physiol. Mol. Plant Pathol. 9:279-283.

17. Jijakli, M. H., and Lepoivre, P. 1998. Characterization of an exo-b-1,3glucanase produced by Pichia anomala strain K, antagonist of Botrytis cinerea on apples. Phytopathology 88:335-343.

18. Karpovich-Tate, N., Spanu, P., and Dewey, F. M. 1998. Use of monoclonal antibodies to determine biomass of Cladosporium. Mol. Plant-
Microbe Interact. 11:710-716.

19. Köhl, J., Bélanger, R. R., and Fokkema, N. J. 1997. Interaction of four antagonistic fungi with Botrytis cinerea in dead onion leaves: A comparative microscopic and ultrastructural study. Phytopathology 87:634642.

20. Köhl, J., and Fokkema, N. J. 1998. Strategies for biological control of necrotrophic fungal foliar pathogens. Pages 49-87 in: Plant-Microbe Interactions and Biological Control. J. Boland, ed. Marcel Dekker Inc., New York.

21. Köhl, J., Gerlagh, M., De Haas, B. H., and Krijger, M. C. 1998. Biological control of Botrytis cinerea in cyclamen with Ulocladium atrum and Gliocladium roseum under commercial growing conditions. Phytopathology 88:568-575.

22. Köhl, J., Molhoek, W. M. L., Van der Plas, C. H., and Fokkema, N. J. 1995. Effect of Ulocladium atrum and other antagonists on sporulation of Botrytis cinerea on dead lily leaves exposed to field conditions. Phytopathology 85:393-401.

23. Köhl, J., Van der Plas, C. H., Molhoek, W. M. L., and Fokkema, N. J. 1995. Effect of interrupted leaf wetness periods on suppression of sporulation of Botrytis allii and Botrytis cinerea by antagonists on dead onion leaves. Eur. J. Plant Pathol. 101:627-637.

24. Larkin, R. P., Roberts, D. P., and Gracia-Garza, J. A. 1998. Biological control of fungal diseases. Pages 149-191 in: Fungicidal Activity. Chemical and Biological Approaches to Plant Protection. D. Hutson and J. Miyamoto, eds. John Wiley \& Sons Ltd., Chichester, NY.

25. Mendgen, K., Hahn, M., and Deising, H. 1996. Morphogenesis and mechanisms of penetration by plant pathogenic fungi. Annu. Rev. Phytopathol. 34:367-386

26. Pitson, S. M., Seviour, R. J., and Mc Dougall, B. M. 1993. Noncellulolytic fungal $\beta$-glucanases: Their physiology and regulation. Enzyme Microbiol. Technol. 15:178-192.

27. Ride, J. P., and Drysdale, R. B. 1972. A rapid method for the chemical estimation of filamentous fungi in plant tissue. Physiol. Mol. Plant Pathol. 2:7-15.

28. Schoene, P., and Köhl, J. 1999. Biological control of Botrytis cinerea by Ulocladium atrum in grapevine and cyclamen. Gesunde Pflanz. 51:81-85.

29. Sesták, S., and Farkas, V. 1996. A ultrasensitive colorimetric method for the assay of endo- $\beta-1,4-D$-glucanase. Biotechnol. Tech. 10:731-734.

30. Somé, A., and Tivoli, B. 1993. Fusarium spp. from potato: Polymorphism of esterase phenotypes on polyacrylamide gel electrophoresis. Agronomie 13:637-649.

31. Sosa-Alvarez, M., Madden, L., and Ellis, M. A. 1995. Effects of temperature and wetness duration on sporulation of Botrytis cinerea on strawberry leaf residues. Plant Dis. 79:609-615.

32. Sutton, J. C., and Peng, G. 1993. Biocontrol of Botrytis cinerea in strawberry leaves. Phytopathology 83:615-621.

33. Wang, G., Michailides, T. J., and Bostock, R. M. 1997. Improved detection of polygalacturonase activity due to Mucor piriformis with a modified dinitrosalicylic acid reagent. Phytopathology 87:161-163.

34. Zamski, E., and Peretz, I. 1996. Cavity spot of carrots: II. Cell-walldegrading enzymes secreted by Pythium and pathogen-related proteins produced by the root cells. Ann. Appl. Biol. 128:195-201.

35. Zimand, G., Elad, Y., and Chet, I. 1996. Effect of Trichoderma harzianum on Botrytis cinerea pathogenicity. Phytopathology 86:1255-1260. 